\title{
Cardiopulmonary bypass simulation at the Boot Camp
}

\author{
George L. Hicks, Jr, MD, ${ }^{\mathrm{a}}$ James Gangemi, MD, ${ }^{\mathrm{b}}$ Ronald E. Angona, Jr, CCP, ${ }^{\mathrm{a}}$ Paul S. Ramphal, DM, ${ }^{\mathrm{c}}$ \\ Richard H. Feins, MD, ${ }^{\mathrm{d}}$ and James I. Fann, $\mathrm{MD}^{\mathrm{e}}$
}

Objective: At Boot Camp, we evaluated a modular approach to skills mastery related to cardiopulmonary bypass and crisis scenarios.

\begin{abstract}
Methods: With 32 first-year cardiothoracic surgery residents divided into 4 groups, 4 consecutive hours were devoted to cardiopulmonary bypass skills by using a perfused nonbeating heart model, computer-controlled CPB simulator, and perfused beating heart simulator. Based on the cardiopulmonary bypass simulator, each resident was assessed by using a checklist rating score on cardiopulmonary bypass management and 1 crisis scenario. An overall cardiopulmonary bypass score was determined. Economy of time and thought was assessed $(1=$ unnecessary/disorganized to $5=$ maximum economy $)$. At the end of the session, residents completed a written examination. Residents rated the sessions on cannulation skills, cardiopulmonary bypass knowledge, and cardiopulmonary bypass emergency and crisis scenarios on a 5 -point scale $(5=$ very helpful to $1=$ not helpful).

Results: Thirty residents completed cardiopulmonary bypass simulator exercises. For initiation and termination of cardiopulmonary bypass, most residents performed the tasks and sequence correctly. Some elements were not performed correctly. For instance, 3 residents did not verify the activated clotting time before cardiopulmonary bypass initiation. Four residents demonstrated inadequate communication with the perfusionist, including lack of assertiveness and unclear commands. In crisis scenarios management of massive air embolism $(\mathrm{n}=8)$ was challenging and resulted in the most errors; poor venous drainage and high arterial line pressure scenarios were managed with fewer errors. For the protamine reaction scenario, all residents $(n=7)$ identified the problem, but in 3 cases heparin was not redosed before resuming cardiopulmonary bypass for right ventricular failure. The score for economy of time and thought was $3.83 \pm 0.6$ (range, 3-5). The score of the written examination was $90.0 \pm 11.3$ (range, 60-100), which did not correlate with the overall cardiopulmonary bypass score of $91.4 \pm 7.1$ (range, $80-100 ; r=0.07)$. The session on acquiring aortic cannulation skills was rated 4.92 , that for cardiopulmonary bypass knowledge was rated 4.96, and that for cardiopulmonary bypass crisis scenarios was rated 4.96.
\end{abstract}

Conclusions: This Boot Camp session introduced residents early in their training to aortic cannulation, principles and management of cardiopulmonary bypass, and crisis management. Based on a modular approach, technical skills and knowledge of cardiopulmonary bypass can be acquired and assessed by using simulations, but further work with more comprehensive educational modules and practice will accelerate the path to mastery of these critical skills. (J Thorac Cardiovasc Surg 2011;141:284-92)

Because of patient-safety concerns, time constraints, changes in resident education requiring more structured training, and more complex procedures in higher-risk patients, simulationbased learning in cardiothoracic surgery has become a topic of increasing interest as the elements of effective simulators

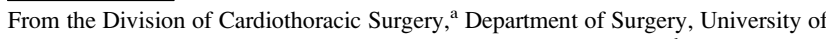
Rochester, Rochester, NY; the Division of Cardiothoracic Surgery, ${ }^{\mathrm{b}}$ Department of Surgery, University of Virginia, Charlottesville, Va; the Department of Surgery, ${ }^{c}$ University of the West Indies, Kingston, Jamaica; the Division of Cardiothoracic Surgery, ${ }^{\mathrm{d}}$ Department of Surgery, University of North Carolina, Chapel Hill, NC; and Division of Cardiothoracic Surgery, ${ }^{\mathrm{e}}$ Department of Surgery, Stanford University and VA Palo Alto, Palo Alto, Calif.

Supported by the Joint Council for Thoracic Surgery Education and the Thoracic Surgery Directors Association.

Disclosures: Authors have nothing to disclose with regard to commercial support.

Received for publication Feb 2, 2010; revisions received March 5, 2010; accepted for publication March 16, 2010; available ahead of print May 10, 2010.

Address for reprints: George L. Hicks, Jr, MD, University of Rochester Medical Center, 601 Elmwood Ave, Rochester, NY 14642 (E-mail: george_hicks@urmc. rochester.edu).

0022-5223/\$36.00

Copyright (C2011 by The American Association for Thoracic Surgery doi:10.1016/j.jtcvs.2010.03.019 are being incorporated into the curriculum. ${ }^{1-7}$ Many academic centers have begun novel initiatives to capture the benefits of simulation in medical student recruitment, increasing general surgery resident exposure, and assessment of cardiothoracic surgical skills. Through these experiences, educators have realized the continued need to expand and adapt simulation-based learning in cardiothoracic surgery to broaden the scope of resident training and to use this modality as one mechanism by which proficiency can be assessed at the residency and postgraduate levels.

The cardiothoracic surgery Boot Camp has evolved over the past 2 years under the auspices of the Thoracic Surgery Directors Association; more recently, the Joint Council on Thoracic Surgery Education has been the catalyst for program directors to explore the use of simulation-based learning in the training programs. The Boot Camp at the University of North Carolina in August 2009 provided focused training for approximately one third of all first-year cardiothoracic surgery residents in the United States. Based on simulation-based learning, 5 areas were emphasized at 


\section{Abbreviations and Acronyms}

$\mathrm{CPB}=$ cardiopulmonary bypass

NOTSS $=$ Non-Technical Skills for Surgeons

OSATS $=$ Objective Structured Assessment of

Technical Skills the Boot Camp: (1) cardiopulmonary bypass (CPB) and cannulation, (2) coronary anastomosis, (3) pulmonary resection, (4) bronchoscopy and mediastinoscopy, and (5) aortic valve surgery. For $\mathrm{CPB}$, the perfused nonbeating heart model provides a low-technology, high-fidelity model for continued practice, whereas the computer-controlled CPB simulator and the perfused beating heart simulator provide hightechnology, high-fidelity models intended for intensive technical and crisis management training. This study was thus focused on a modular approach to the mastery of skills related to CPB and crisis scenarios and the assessment of these skills.

\section{MATERIALS AND METHODS}

Thirty-two first-year cardiothoracic surgery residents, all having completed general surgery residency training, participated in the $2^{1} / 2$-day Boot Camp at the Friday Center for Continuing Education at the University of North Carolina. Residents' previous experience in cardiac surgery was limited to less than 1 month of formal training in adult cardiac surgery. With the 32 residents randomly divided into 4 groups (each with 8 residents), 4 consecutive hours were devoted to training in aortic cannulation and CPB skills. Approval was obtained from the Institutional Review Board at the University of North Carolina to review and analyze the data.

\section{Simulation Laboratory}

For the CPB session, the center was configured to provide 3 operating areas with 3 different simulators. Each resident rotated through all 3 stations. The stations were equipped with task lighting, surgical instruments, and sutures. Surgical gowns and gloves were provided, and loupe magnification, if necessary, was used by the participants.

\section{CPB Stations}

Perfused nonbeating heart model. This partial-task simulator was constructed by using a porcine heart with the ascending, arch, and descending thoracic aorta intact. The hearts were prepared by oversewing the coronary sinus, pulmonary artery, and aortic arch vessels. The aorta extending to the descending thoracic aorta was cannulated and connected through intravenous tubing to a pressurized bag of saline. The porcine heart model was placed in a metal container and draped (Figure 1). The pressurized ascending aorta allowed placement of purse-string sutures in the constructed ascending aorta and the right atrium for cannulation. Because of the long length of the aorta with the model, multiple aortic cannulations were performed.

CPB simulator. The perfusion or CPB simulator (Orpheus Simulator; Ulco Technologies, Marrickville, New South Wales, Australia) is an interactive, high-fidelity, computer-controlled simulator used in the training of perfusionists and surgeons (Figure 2). ${ }^{8}$ The plastic thorax with a silicone rubber heart model and inflow and outflow lines were part of the simulator station. It includes software to simulate multiple physiologic and pharmacologic conditions and scenarios, providing parameters such as heart rhythm,

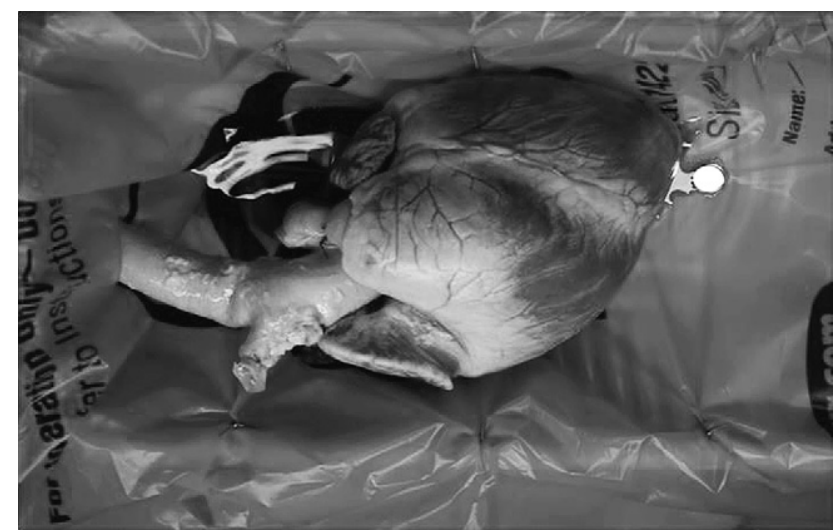

FIGURE 1. Perfused nonbeating porcine heart model in a container. The arch vessels are oversewn, and a portion of the descending aorta in continuity with the ascending aorta provides a long segment of aorta to perform multiple aortic cannulations and placement of an antegrade cardioplegia catheter.

systemic vascular resistance, and oxygen saturation. The trainees were assessed on their ability to manage the steps preceding and during $\mathrm{CPB}$, including understanding the setup of the $\mathrm{CPB}$ circuit and requirements for instituting and weaning from CPB. Additionally, residents were assessed on potential $\mathrm{CPB}$ mishaps and their reaction to and ability to manage emergency and crisis scenarios.

Perfused beating heart simulator. This high-fidelity simulator has been described previously (Figure 3 ). ${ }^{6}$ In brief, latex balloons were inserted into the left ventricular cavity and right ventricle of a porcine heart through the pulmonary venous orifices and superior vena cava, respectively. The prepared heart is placed in a simulated pericardial well and thoracic cavity. The tubes to the intraventricular balloons exited the pericardial well and were connected to the computer-controllable pumping mechanism. The aorta was brought through a tunnel in the cephalad end of the pericardial well, and the open end was clamped. The porcine heart was fixed at 4 points, with 2 points being at the inflow of the pneumatic lines, thus allowing the heart to beat realistically in a pericardial well. A perfusion line introduced into the aortic arch was connected to a roller pump, which operated in series

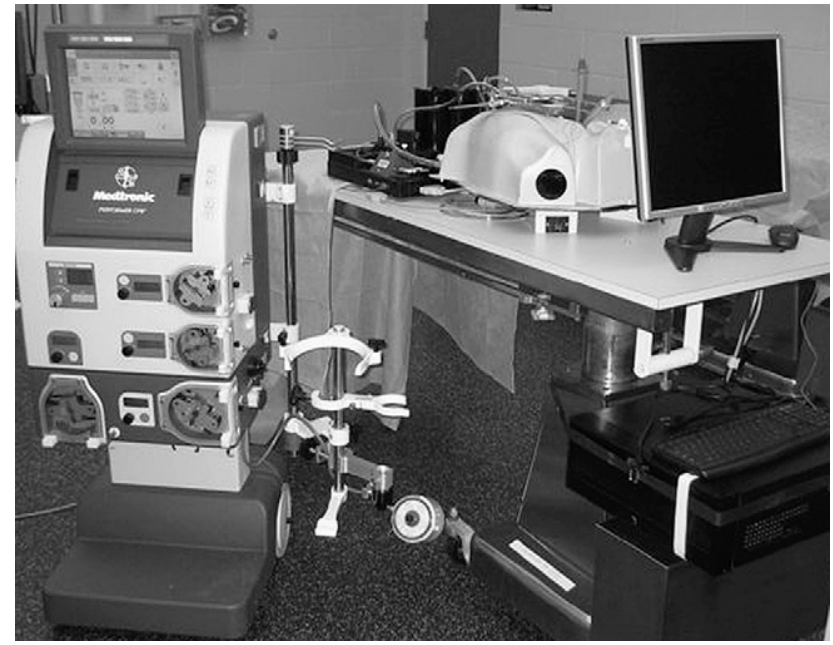

FIGURE 2. The Silastic heart model is placed in a plastic thorax and attached to the Orpheus cardiopulmonary bypass simulator. This simulation exercise allows the resident to understand the cardiopulmonary bypass circuit and to participate in emergency and crisis management. 

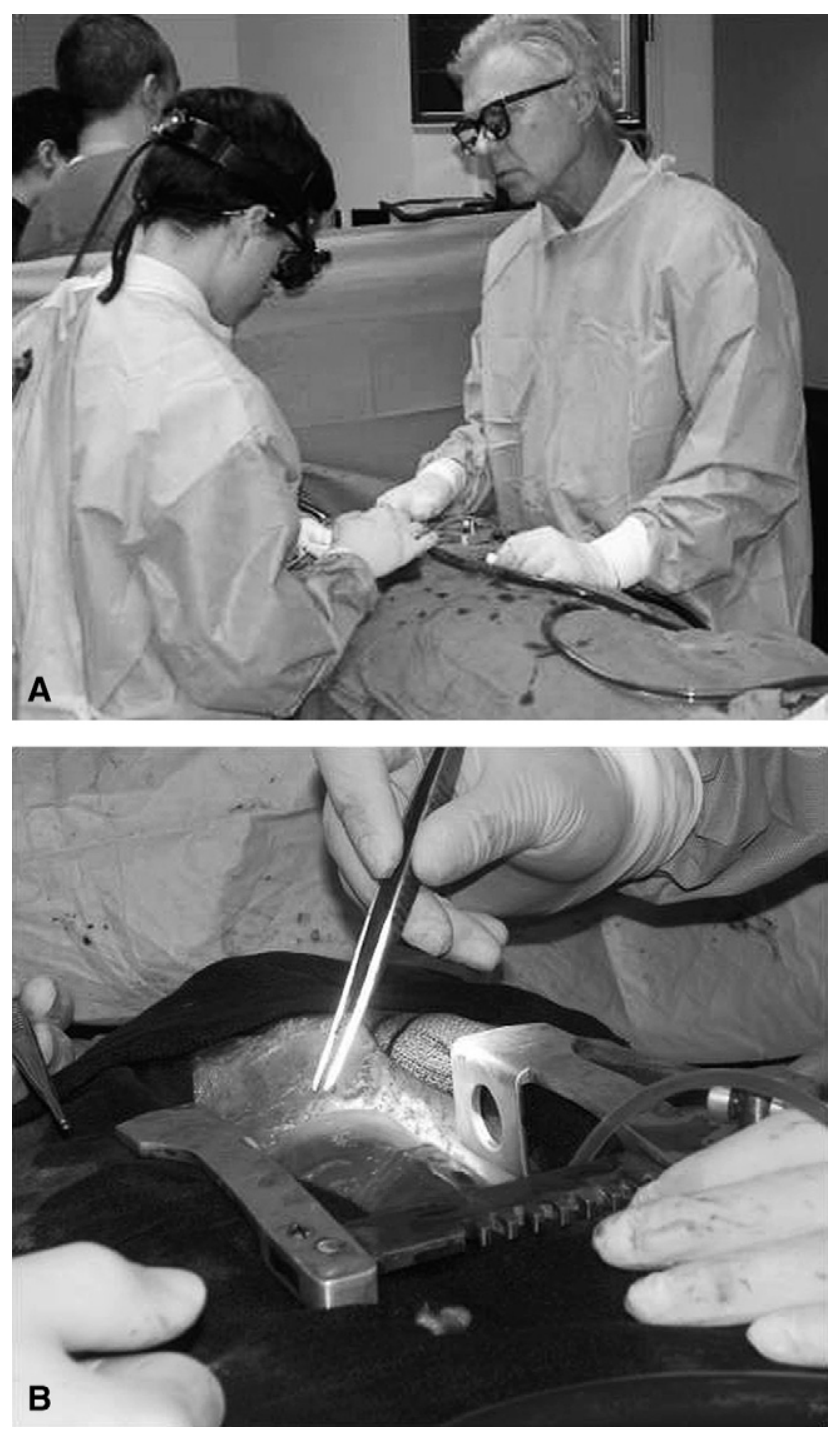

FIGURE 3. The perfused beating heart simulator is a high-fidelity, computer-controlled cardiac simulator that allows the trainee to perform tasks critical to the institution of cardiopulmonary bypass and to integrate his or her knowledge regarding emergency and crisis scenarios.

with another roller pump, which in turn served as an intraoperative pericardial sump suction; the simulated blood was continuously circulated through the coronary vasculature and atrial and ventricular chambers and then out through the inferior vena cava to a reservoir for recirculation. By using this preparation, it was possible to place the beating heart on bypass with standard aortic and right atrial cannulation techniques.

A computer controlled the intraventricular pumping mechanism of the simulator. An intraoperative monitor controlled by the simulation software and synchronized to the mechanical activity of the pump provided physiological parameters, including electrocardiography; systemic arterial, central venous, and pulmonary arterial pressure tracings; and core body temperature.

\section{Simulation Protocol}

Before this session, the residents were provided with and encouraged to review study materials regarding $\mathrm{CPB}$, including its components, safeguards, and management during on-pump surgery. ${ }^{9}$ The residents were given a 20-minute orientation to the CPB simulator, outlining the correct steps in initiating and terminating CPB. The following are the specific skills at each station.

First, cannulation techniques were performed with the perfused nonbeating heart model. The focus was to demonstrate and have the resident perform the various techniques of cannulating the aorta and right atrium. By using this model, the residents placed 2 polyester purse-string sutures (2-0 Ethibond with pledgets; Ethicon, Somerville, NJ) in the pressurized ascending aorta; a tourniquet and hemostat were placed on the suture. A small aortotomy was made followed by the placement of an 8-mm Sarns Soft-flow aortic cannula (Terumo Cardiovascular System, Ann Arbor, Mich), which was secured with a 0-silk suture (Ethicon). The cannula was deaired and connected to the arterial return line, which in turn was secured to the drape. A 3-0 polypropylene suture (Prolene, Ethicon) was placed around the right atrial appendage, and a tourniquet was applied. The appendage was removed, and a $32 \mathrm{~F}$ venous cannula was inserted into the right atrium and connected to the venous line, which was secured to the drape. The terminology of deairing the line, checking line pressure, checking activated clotting time, removing the tubing clamp, and "going on bypass" was reinforced. Each resident was given the opportunity to practice these maneuvers and provided with formative feedback but no direct assessment.

Second, each resident participated in the use of the CPB simulator (Orpheus Simulator), which provided a realistic experience in a normal setting, as well as during periods of crisis or emergency. This session was conducted by a faculty member and a perfusionist. Each resident proceeded to manage the $\mathrm{CPB}$ process, initiating and terminating $\mathrm{CPB}$, followed by 1 emergency or crisis scenario. The residents were formally assessed in the management of CPB and 1 critical CPB emergency, including massive air embolism, poor venous drainage, high arterial line pressure (including aortic dissection), or protamine reaction (Table 1). Feedback was given to residents, and their performance, including correct actions and errors, was discussed.

Third, the perfused beating heart station provided the resident an opportunity to integrate their knowledge regarding $\mathrm{CPB}$ and their responses to emergency scenarios in a highly realistic setting under the direction of a faculty member. Typical cannulation exercises were carried out similar to that on the nonbeating perfused heart model, and adverse events were presented and discussed. This station was a one-on-one session with active interchange and feedback. Given the dialogue quality of this component of simulation, there was no formal assessment of resident performance.

Fourth, at the conclusion of the session, all residents completed a written examination with 10 multiple-choice questions to evaluate their understanding of $\mathrm{CPB}$. The examination focused on various components of $\mathrm{CPB}$, including acceptable line pressures, patients' temperatures, systemic hypertension and hypotension, rewarming strategies, assessment of cardiac and pulmonary function, and crises, such as aortic dissection and air embolism.

\section{Performance Assessment}

Each resident was directly supervised by a dedicated faculty surgeon during all sessions; formative feedback was given to the resident at all stations. There was no formal assessment for the perfused nonbeating heart model and the perfused beating heart simulator. For the CPB simulator, the residents were introduced to normal $\mathrm{CPB}$ physiology and crisis scenarios and were evaluated by using an assessment form based on elements from the Objective Structured Assessment of Technical Skills (OSATS) and the Southern Illinois University Verification of Proficiency, including a checklist and overall 5-point rating on economy of time and thought (Table 1). ${ }^{10-14}$ Also, elements of nontechnical skills assessment from the Non-Technical Skills for Surgeons (NOTSS) developed at the University of Aberdeen were incorporated. ${ }^{15}$ Assessment of competence was based on performance on the CPB simulator, including understanding of CPB skills and techniques. An overall score was then assigned based on whether the error was a major deficiency ( -10 points) or a minor deficiency ( -5 points). Major deficiencies included errors that would result in a poor clinical outcome, such as not recognizing or identifying the cause of the emergency, and minor deficiencies included those steps that would not result in a serious morbidity. 
TABLE 1. Evaluation checklist and rating scale of cardiopulmonary bypass and emergency and crisis scenarios Cardiopulmonary bypass

Resident

Date

Evaluator

\section{Steps}

Initiation

Ensure adequate activated clotting time

Communicate with perfusionist

Check line pressure

Assess venous drainage

Vent placement

Cardioplegia

Crossclamp

Termination

Removal of crossclamp

Deairing procedures

Vent removal

Weaning CPB

Ventilator is on

Temperature satisfactory

TEE to assess intracardiac air

TEE to assess cardiac function

No bleeding in inaccessible areas

Acceptable rhythm/pacing wires

Need for inotropic support

Termination of bypass

Decannulation

Emergency scenario 1

Massive air embolism

Recognition of problem in appropriate time

Communicates problem to perfusionist

Correct response to problem

Immediately stop pump

Clamp arterial cannula

Trendelenberg position

Remove cannula, deair

Retrograde cerebral perfusion

Replace cannula, reinstitute CPB

Cooling

Emergency scenario 2

Poor venous drainage

Recognition of problem in appropriate time

Responds to perfusionist's concerns

Correct response to problem

On initiation of CPB

Ensure correct cannula placement

Examine line for kinks and crimps

Minimize venous air

Eliminate hypovolemia as a cause

During CPB

Cannula migration

Heart turned for anastomoses

Identifies potential for vacuum-assisted venous drainage
$\mathrm{Y}$

Y

Y

Y

$\mathrm{Y}$

Y

Y

Y

Y

Y

Y

Y

Y

Y

Y

Y

Y

Y

Y

$\mathrm{N}$

$\mathrm{N}$

$\mathrm{N}$

N

$\mathrm{N}$

N

$\mathrm{N}$

$\mathrm{N}$

$\mathrm{N}$

$\mathrm{N}$

N

N

$\mathrm{N}$

$\mathrm{N}$

$\mathrm{N}$

N

N

$\mathrm{N}$

$\mathrm{N}$

$\mathrm{N}$

$\mathrm{N}$

$\mathrm{N}$

N

$\mathrm{N}$

$\mathrm{N}$

$\mathrm{N}$

$\mathrm{N}$

$\mathrm{N}$

$\mathrm{N}$

$\begin{array}{ll}\mathrm{Y} & \mathrm{N} \\ \mathrm{Y} & \mathrm{N} \\ \mathrm{Y} & \mathrm{N} \\ \mathrm{Y} & \mathrm{N} \\ & \\ \mathrm{Y} & \mathrm{N} \\ \mathrm{Y} & \mathrm{N} \\ \mathrm{Y} & \mathrm{N}\end{array}$




\begin{tabular}{|c|c|c|}
\hline Steps & Satisfactory & Commen \\
\hline \multicolumn{3}{|l|}{ Emergency scenario 3} \\
\hline \multicolumn{3}{|l|}{ High arterial line Pressure } \\
\hline Recognition of problem in appropriate time & Y & $\mathrm{N}$ \\
\hline Responds to perfusionist's concerns & $\mathrm{Y}$ & $\mathrm{N}$ \\
\hline \multicolumn{3}{|l|}{ Correct response to problem } \\
\hline \multicolumn{3}{|l|}{ High line pressure when cannulating } \\
\hline Cannula in true lumen? & Y & $\mathrm{N}$ \\
\hline Cannula correctly oriented? & $\mathrm{Y}$ & $\mathrm{N}$ \\
\hline CPB transducers zeroed correctly? & $\mathrm{Y}$ & $\mathrm{N}$ \\
\hline \multicolumn{3}{|l|}{ High line pressure at aortic crossclamping } \\
\hline Clamp placed across cannula? & Y & $\mathrm{N}$ \\
\hline \multicolumn{3}{|l|}{ High line pressure during $\mathrm{CPB}$} \\
\hline Line kinked? & $\mathrm{Y}$ & $\mathrm{N}$ \\
\hline Surgical personnel leaning on line? & $\mathrm{Y}$ & $\mathrm{N}$ \\
\hline High systemic vascular resistance? & Y & $\mathrm{N}$ \\
\hline Bad arterial line? & $\mathrm{Y}$ & $\mathrm{N}$ \\
\hline \multicolumn{3}{|l|}{ Aortic dissection } \\
\hline Stop CPB & $\mathrm{Y}$ & $\mathrm{N}$ \\
\hline Clamp arterial and venous lines & $\mathrm{Y}$ & $\mathrm{N}$ \\
\hline Confirm diagnosis visual or TEE & $\mathrm{Y}$ & $\mathrm{N}$ \\
\hline Rule out kinked or obstructed line & $\mathrm{Y}$ & $\mathrm{N}$ \\
\hline Remove arterial cannula to alternate site & Y & $\mathrm{N}$ \\
\hline Resume CPB, cool to DHCA, repair & $\mathrm{Y}$ & $\mathrm{N}$ \\
\hline \multicolumn{3}{|l|}{ Emergency scenario 4} \\
\hline \multicolumn{3}{|l|}{ Protamine reaction } \\
\hline Recognition of problem in appropriate time & Y & $\mathrm{N}$ \\
\hline \multicolumn{3}{|l|}{ Appropriate response } \\
\hline Institute $100 \% \mathrm{O}_{2}$ & $\mathrm{Y}$ & $\mathrm{N}$ \\
\hline IV fluids, steroids & Y & $\mathrm{N}$ \\
\hline Antihistamines, vasoconstrictors, bronchodilators & Y & $\mathrm{N}$ \\
\hline Resume $\mathrm{CPB}$ if right ventricular failure & Y & $\mathrm{N}$ \\
\hline Recognizes need to reheparinize & $\mathrm{Y}$ & $\mathrm{N}$ \\
\hline
\end{tabular}

Economy of time and thought*

1

2

3

4

5

Final rating (circle one)

Demonstrates competence

Needs further practice

$\overline{C P B}$, Cardiopulmonary bypass; TEE, transesophageal echocardiography; $D H C A$, deep profound hypothermic circulatory arrest; $I V$, intravenous. * $1=$ Many unnecessary/disorganized questions and comments/thought, $3=$ organized time and comments/thought with some unnecessary questions/comments, $5=$ maximum economy of thought and efficiency.

\begin{abstract}
Assessment of resident knowledge was also based on a 10-question multiple-choice examination. At the conclusion of Boot Camp, the residents rated the importance and value of the sessions on acquiring cannulation skills, CPB knowledge, and CPB emergency and crisis scenarios on a 5 -point scale $(5=$ very helpful, $4=$ helpful, $3=$ average, $2=$ slightly helpful, and $1=$ not helpful).
\end{abstract}

\section{Data Analysis}

The assessment data forms were reviewed, and results were tabulated. The data are reported as means \pm standard deviations. Pearson's coefficient was calculated to detect the presence of correlation of resident performance by using the $\mathrm{CPB}$ simulator with the written test scores.

\section{RESULTS}

\section{Initiation and Termination of CPB}

All 32 residents underwent training at the 3 simulation stations; 30 residents completed CPB simulation and emergency scenarios by using the CPB simulator and were assessed by using the checklist and overall rating score. For initiation and termination of $\mathrm{CPB}$, the vast majority of residents performed the tasks and sequence correctly (Table 2). A number of elements were considered major errors with serious clinical consequences; for instance, 3 residents did not verify the activated clotting time before institution of $\mathrm{CPB}$, and 3 residents did not ensure that the ventilator was on during weaning from CPB. Other important components included inadequate communication with the perfusionist, including lack of assertiveness and unclear commands, in 4 cases. No bleeding in inaccessible areas was often overlooked because the residents were focused on the components of CPB. Of interest was the number of residents who did not adequately use transesophageal echocardiographic analysis to assess 
TABLE 2. Resident's performance in initiation and termination of cardiopulmonary bypass $(n=30)$

\begin{tabular}{lll}
\hline & \multicolumn{2}{c}{ Satisfactory } \\
\cline { 2 - 3 } \multicolumn{1}{c}{ Steps } & Y & N \\
\hline Initiation & & \\
Ensure adequate activated clotting time & 27 & 3 \\
Communicate with perfusionist & 26 & 4 \\
Check line pressure & 29 & 1 \\
Assess venous drainage & 29 & 1 \\
Vent placement & Not scored & \\
Cardioplegia & Not scored & \\
Crossclamp & Not scored & \\
Termination & & \\
Removal of crossclamp & Not scored & \\
Deairing procedures & Not scored & \\
Vent removal & Not scored & \\
Weaning CPB & & \\
Ventilator is on & 27 & 3 \\
Temperature satisfactory & 27 & 3 \\
TEE to assess intracardiac air & 21 & 9 \\
TEE to assess cardiac function & 25 & 5 \\
No bleeding in inaccessible areas & 25 & 5 \\
Acceptable rhythm/pacing wires & 30 & 0 \\
Need for inotropic support & 28 & 2 \\
Termination of bypass & & \\
Decannulation & & \\
$C P B$ Cardiopulmonary bypass; $T E E$, transesophageal echocardiography. &
\end{tabular}

for intracardiac air or left ventricular function. Although vent placement, cardioplegia, and crossclamping were on the assessment form, they were not directly rated with this simulator.

\section{CPB Emergency and Crisis Management}

Regarding CPB crisis management scenarios, it was evident that massive air embolism $(n=8)$ was the most challenging and resulted in the most errors (Table 3). Three of 8 residents did not recognize the problem in a timely fashion. Five of the residents did not stop the CPB pump, and 3 did not clamp the arterial cannula. Scenarios involving poor venous drainage $(n=8)$ and high arterial line pressure $(n=7)$ were managed much better by the residents with fewer errors (Tables 4 and 5). For the protamine reaction scenario, all residents $(n=7)$ identified the problem, but a critical error in 3 cases was not redosing the heparin before resuming CPB for right ventricular failure (Table 6).

\section{Overall CPB Score}

By defining major ( -10 points) and minor ( -5 points) errors during $\mathrm{CPB}$ performance (initiation and termination of $\mathrm{CPB}$ and emergency scenario), the mean overall CPB score was $91.4 \pm 7.1$ (range, 80-100). Based on the checklist and interactions during the session, an assessment (1- to 5-point scale) of economy of time and thought demonstrated a mean score of $3.83 \pm 0.6$ (range, 3-5). Assessment of competence
TABLE 3. Resident's performance in massive air embolism during cardiopulmonary bypass

\begin{tabular}{lcc}
\hline \multicolumn{1}{c}{ Emergency scenario } & \multicolumn{2}{c}{ Total residents: 8 } \\
\cline { 2 - 3 } & $\mathbf{Y}$ & $\mathbf{N}$ \\
\hline Massive air embolism & 5 & 3 \\
Recognition of problem in appropriate time & 7 & 1 \\
Communicates problem to perfusionist & & \\
Correct response to problem & 3 & 5 \\
$\quad$ Immediately stop pump & 5 & 3 \\
Clamp arterial cannula & 6 & 2 \\
Trendelenberg position & 7 & 1 \\
Remove cannula, deair & Not scored & \\
Retrograde cerebral perfusion & 8 & 0 \\
Replace cannula, reinstitute CPB & 8 & 0 \\
Cooling & & \\
\hline$C P B$, Cardiopulmonary bypass. &
\end{tabular}

$C P B$, Cardiopulmonary bypass.

was mainly based on performance on the defined exercises by using the CPB simulator; in general, all residents were considered to have "demonstrated competence" at the conclusion of the session in acquiring CPB skills, although only 5 residents performed all the tasks correctly. Given the complexity of CPB management and the multitude of potential catastrophes, it is acknowledged that additional practice and clinical experience are critically necessary.

\section{Written Examination}

The mean score of the 10-question written examination was $90.0 \pm 11.3$ (range, $60-100$ ). There was no correlation between the written examination and the overall CPB score $(r=0.07)$.

\section{Residents' Ratings}

The residents rated the importance and value of the sessions on acquiring cannulation skills, CPB knowledge, and $\mathrm{CPB}$ emergency and crisis scenarios. On a 5-point scale and based on a total of 26 responses, the session on acquiring aortic cannulation skills was rated 4.92, that for CPB knowledge was rated 4.96 , and that for CPB emergency and crisis scenarios was rated 4.96 .

\section{DISCUSSION}

The intent of the Boot Camp session was to introduce residents early in their training to aortic cannulation, principles and management of $\mathrm{CPB}$, and crisis management with onpump surgery; an additional focus was the development of a method of assessment for these simulation tasks and procedures. Although technical skills and knowledge of CPB can be simulated as shown in this study, further work in this area using principles of distributed and deliberate practice and comprehensive educational modules will accelerate the path to mastery of critical skills. ${ }^{16-18}$

Simulation-based learning has become an important component in the evolution of the cardiothoracic surgery 
TABLE 4. Resident's performance in poor venous drainage during cardiopulmonary bypass

\begin{tabular}{lcc}
\hline & \multicolumn{2}{c}{ Total residents: 8 } \\
\cline { 2 - 3 } Emergency scenario & $\mathbf{Y}$ & $\mathbf{N}$ \\
\hline Poor venous drainage & & \\
Recognition of problem in appropriate time & 8 & 0 \\
Responds to perfusionist's concerns & 8 & 0 \\
Correct response to problem & & \\
On initiation of CPB & & \\
$\quad$ Ensure correct cannula placement & 8 & 0 \\
$\quad$ Examine line for kinks and crimps & 8 & 0 \\
$\quad$ Minimize venous air & 8 & 0 \\
$\quad$ Eliminate hypovolemia as a cause & 5 & 3 \\
During CPB & & \\
Cannula migration & 7 & 1 \\
Heart turned for anastomoses & 8 & 0 \\
Identifies potential for vacuum-assisted & 6 & 2 \\
$\quad$ venous drainage & & \\
\hline$C P B$, Cardiopulmonary bypass. & &
\end{tabular}

educational curriculum. ${ }^{1-7}$ Such learning early in residency permits the resident to interact in a less stressful environment and might be useful in preparing the resident for the clinical setting. ${ }^{10,19}$ Despite the progress to date, many aspects of simulation in cardiothoracic surgery remain to be developed. Importantly, the need for assessment tools of technical and nontechnical skills and their validation and reliability are paramount if simulation is to be universally adopted and applied to proficiency-based advancement and potentially board certification examinations. Performance assessment in cardiothoracic surgery simulation has been previously reported. ${ }^{2,3,7}$ In this study we modified existing performance measures, including the OSATS, Southern Illinois University Verification of Proficiency, and NOTSS, to generate a working assessment tool to document residents' performance during simulated CPB training. ${ }^{10-15}$

Based on a modular approach, the vast majority of residents in this study performed the tasks and sequence correctly in initiating and terminating CPB. There are a number of elements in the assessment that warrant further analysis. For instance, not verifying the activated clotting time before institution of CPB or not redosing the heparin (after protamine has been given) to resume $\mathrm{CPB}$ during a protamine reaction can have potentially serious clinical consequences.

Also underappreciated is the surgeon-perfusionist interaction, which is not always acknowledged during residency training. In this study some residents demonstrated inadequate communication skills with the perfusionist, including lack of assertiveness and unclear commands. Faculty recognition of the importance of this skill, part of which includes a unique vocabulary and gestures, is imperative when training residents.

Other elements, such as ensuring that the patient is ventilated and that the patient's temperature is adequate when
TABLE 5. Resident's performance in high arterial line pressure and aortic dissection during cardiopulmonary bypass

\begin{tabular}{lll}
\hline & \multicolumn{2}{c}{ Total residents: 7 } \\
\cline { 2 - 3 } Emergency scenario & $\mathbf{Y}$ & $\mathbf{N}$ \\
\hline High arterial line pressure & & \\
Recognition of problem in appropriate time & 7 & 0 \\
Responds to perfusionist's concerns & 7 & 0 \\
Correct response to problem & & \\
High line pressure when cannulating & & \\
$\quad$ Cannula in true lumen? & 7 & 0 \\
$\quad$ Cannula correctly oriented? & 6 & 1 \\
$\quad$ CPB transducers zeroed correctly? & 6 & 1 \\
High line pressure at aortic crossclamping & & \\
$\quad$ Clamp placed across cannula? & 7 & 0 \\
High line pressure during CPB & & \\
$\quad$ Line kinked? & 7 & 0 \\
Surgical personnel leaning on line? & 7 & 0 \\
High systemic vascular resistance? & 7 & 0 \\
$\quad$ Bad arterial line? & 7 & 0 \\
Aortic dissection & & \\
Stop CPB & 6 & 1 \\
Clamp arterial and venous lines & 6 & 1 \\
Confirm diagnosis visual or TEE & 6 & 1 \\
Rule out kinked or obstructed line & 6 & 1 \\
Remove arterial cannula to alternate site & 6 & 1 \\
Resume CPB, cool to DHCA, repair & 6 & 1 \\
\hline$C P B$, Cardiopulmonary bypass; TEE, transesophageal echocardiography; & $D H C A$ \\
deep profound hypothermic circulatory arrest. & &
\end{tabular}

weaning from $\mathrm{CPB}$, are also important in the conduct of $\mathrm{CPB}$. In the clinical setting, although some of these components are often checked by other members of the surgical team, including the anesthesiologist and perfusionist, the surgeon is responsible for ensuring that all these components and elements are properly performed. Interestingly, a number of residents did not adequately use transesophageal echocardiographic analysis to assess for intracardiac air or left ventricular function. Because of the complexity of CPB management and the amount of information that was presented at this session, transesophageal echocardiographic analysis, which requires additional skills that the residents did not have at this stage in their training, was neglected. As the resident achieves more comfort with CPB and understands the need to assess intracardiac air after open cardiac procedures, this element must become part of the resident's personal checklist.

Checking for hemostasis (ie, no bleeding in inaccessible areas) was often overlooked because the residents were focused on the components of CPB. It can be argued that in the clinical setting the bleeding would be obvious, and because the assessment was carried out on a CPB simulator and not the porcine heart simulator, it is understandable why this element was neglected.

Regarding crisis scenarios, air embolism was the most challenging and resulted in the most errors by the residents. The elements defined in the management of this scenario 
TABLE 6. Resident's responses in protamine reaction during cardiopulmonary bypass

\begin{tabular}{lll}
\hline & \multicolumn{2}{c}{ Total residents: 7 } \\
\cline { 2 - 3 } Emergency scenario & $\mathbf{Y}$ & $\mathbf{N}$ \\
\hline Protamine reaction & & \\
Recognition of problem in appropriate time & 7 & 0 \\
Appropriate response & & \\
$\quad$ Institutes $100 \% \mathrm{O}_{2}$ & 6 & 1 \\
IV fluids, steroids & 6 & 1 \\
Antihistamines, vasoconstrictors, bronchodilators & 6 & 1 \\
Resume CPB if right ventricular failure & 7 & 0 \\
Recognizes need to reheparinize & 4 & 3 \\
\hline
\end{tabular}

$I V$, Intravenous; $C P B$, cardiopulmonary bypass.

are critically important in the clinical setting; such performance reinforces the need to practice this scenario. Because of the structure of the Boot Camp sessions, not all residents were exposed to the air embolism scenario. In future sessions it would be valuable to present this scenario to all residents.

In this study the method of assessment was relatively straightforward and documented what we considered to be important elements of CPB. However, during the sessions, there were hesitations, interactions, and prompts that could not be easily captured by using a checklist. Also, the complexity of CPB incorporating relatively advanced technical skills coupled to defined routine and crisis management requires the synthesis of various assessment tools, such as specific and global ratings scales (eg, OSATS) and assessment of nontechnical skills (eg, NOTSS). The assessment tool in this study is such an attempt to provide a comprehensive yet manageable method of measuring performance regarding CPB. This rating scale might not detect all the important features of the tasks, however, and further work and experience will continue to refine this assessment tool. As we gain experience, deficiencies relating to situational awareness, decision making, communication and teamwork, and leadership (ie, NOTSS) will need to be better embedded in our assessment. ${ }^{15}$

In view of the challenges of developing high-technology simulators, existing simulators and low-technology devices provide reasonable and reliable source of training and assessment in many aspects of cardiothoracic surgery. ${ }^{2,3,7}$ By using a modular approach, current low-technology simulators and the high-technology CPB simulator developed for training of perfusionists are well suited to $\mathrm{CPB}$ training for cardiothoracic surgery residents. As demonstrated at the Boot Camp, residents can use the perfused nonbeating heart model for aortic and atrial cannulation and decannulation skills and more advanced simulators to master the steps for initiation and termination of CPB. Additionally, various emergency scenarios and crisis management can be rehearsed by using novel low-technology simulators; when situated in a high-fidelity perfused beating heart station or human performance simulation laboratory, such scenarios become much more dramatic. ${ }^{6}$ Resident acceptance of structured simulation has been positive, and the opportunity to be allowed to make and learn from mistakes in a low-stress environment is extremely appealing. For simulation-based learning to be successful and widely adopted, faculty development at academic centers needs to be better defined. Junior faculty engaged in resident education and simulation development need to be recognized in the faculty promotion process, and activities related to education need to be perceived as representing real value in one's academic career. Additionally, the cost of simulation-based learning, both in terms of equipment and faculty time, must be recognized at the institutional and national levels so that funds become available for this innovative approach to education.

In general, an important limitation is that simulators do not fully reproduce the tissue response seen in human pathoanatomy. Typically, the human ascending aorta is without significant disease, and thus the pressurized porcine aorta is a realistic representation or model for aortic cannulation and decannulation. One concern is that the Boot Camp training was 4 hours of massed practice with no assessment of long-term skill retention. Therefore the findings in this study are considered preliminary, and a more comprehensive approach with distributed practice and longitudinal assessment will be necessary. For the emergency and crisis scenarios, the resident's performance was evaluated by the faculty and grounded by one perfusionist with many years of experience who was present at all the sessions; recognizing issues with bias and reliability of one assessor, our approach, although not ideal, did provide important information regarding CPB management given the checklist format of our assessment form. Although somewhat arbitrary, major and minor errors were determined based on their relative effect in the clinical setting, and a more systematic approach to weigh such effects is being investigated. The issue of whether the improved performance at the Boot Camp is transferable to the operating room was not addressed in this study, and further follow-up evaluations will be necessary.

In conclusion, focused training at the Boot Camp provided the residents with an opportunity to practice aortic cannulation and understand the principles of CPB. Our study showed that a modular approach to cannulation and CPB training and an assessment of the technical and nontechnical skills can be implemented. However, retention of these skills and building them to a level of mastery require deliberate and distributed practice and faculty commitment. The Boot Camp is but one method of augmenting early resident training, and the need for a structured curriculum for simulationbased learning is emphasized as surgical educators develop simulators and skills laboratories.

We thank Daniel N. Coore, $\mathrm{PhD}$, for his assistance in setting up the perfused beating heart simulator and the faculty participants in this session. We thank the resident participants of the Boot Camp 
for their assistance with this project and for providing us with feedback. We also thank Beth Winer, Nancy Gray Puckett, Joyce A. Gambino, Sharon Porta, and Rebecca J. Mark for their assistance in the organization of the Boot Camp. Corporate sponsors for this session included Maquet Cardiovascular, Medtronic, St Jude Medical, Sorin Group, Scanlan International, Teleflex Medical, and Ethicon.

\section{References}

1. Carpenter AJ, Yang SC, Uhlig PN, Colson YL. Envisioning simulation in the future of thoracic surgical education. J Thorac Cardiovasc Surg. 2008;135:477-84.

2. Fann JI, Caffarelli AD, Georgette G, Howard SK, Gaba DM, Youngblood P, et al. Improvement in coronary anastomosis with cardiac surgery simulation. J Thorac Cardiovasc Surg. 2008;136:1486-91.

3. Fann JI, Calhoon JH, Carpenter AJ, Merrill WH, Brown JW, Poston RS, et al. Simulation in coronary artery anastomosis early in cardiothoracic surgical residency training: the Boot Camp experience. J Thorac Cardiovasc Surg. 2009 [Epub ahead of print].

4. Hicks GL Jr, Brown JW, Calhoon JH, Merrill WH. You never know unless you try. J Thorac Cardiovasc Surg. 2008;136:814-5.

5. Feins RH. Expert commentary: cardiothoracic surgical simulation. J Thorac Cardiovasc Surg. 2008;135:485-6.

6. Ramphal PS, Coore DN, Craven MP, Forbes NF, Newman SM, Coye AA, et al. A high fidelity tissue-based cardiac surgical simulator. Eur J Cardiothorac Surg. 2005;27:910-6.

7. Carter YM, Marshall MB. Open lobectomy simulator is an effective tool for teaching thoracic surgical skills. Ann Thorac Surg. 2009;87:1546-50.
8. Morris RW, Pybus DA. “Orpheus"' cardiopulmonary bypass simulation system. J Extra Corpor Technol. 2007;39:228-33.

9. TSDA Boot Camp 2009 Web site: introduction to cardiopulmonary bypass. Available at:http://www.tsda.org/documents/PDF/Boot\%20Camp\%20Docs/ Boot $\% 20$ Camp\%202009/CPB_Skills.09.Print_Version.pdf. Accessed January $10,2010$.

10. Reznick RK, MacRae H. Teaching surgical skills—changes in the wind. $N$ Engl J Med. 2006;355:2664-9.

11. Reznick R, Regehr G, MacRae H, Martin J, McCulloch W. Testing technical skill via an innovative "bench station"' examination. Am J Surg. 1996;172:226-30.

12. Martin JA, Regehr G, Reznick R, MacRae H, Murnaghan J, Hutchison C, et al. Objective structured assessment of technical skill (OSATS) for surgical residents. Br J Surg. 1997;84:273-8.

13. Southern Illinois University Verification of Proficiency Web site. Available at: http://www.siumed.edu/surgery/surgical_skills/verification_of_proficency.html. Accessed January 10, 2010.

14. Beard JD, Jolly BC, Newbie DI, Thomas WEG, Donnelly TJ, Southgate LJ. Assessing the technical skills of surgical trainees. Br J Surg. 2005;92:778-82.

15. Yule S, Flin R, Maran N, Rowley D, Youngson G, Paterson-Brown S. Surgeons' non-technical skills in the operating room: reliability testing of the NOTSS behavior rating system. World J Surg. 2008;32:548-56.

16. Ericsson KA, Krampe RT, Tesch-Romer C. The role of deliberate practice in the acquisition of expert performance. Psychol Rev. 1993;100:363-406.

17. Donovan JJ, Radosevich DJ. A meta-analytic review of the distribution of practice effect: now you see it, now you don't. J Appl Psychol. 1999;84:795-805.

18. Moulton CA, Dubrowski A, MacRae H, Graham B, Grober E, Reznick R. Teaching surgical skills: What kind of practice makes perfect? Ann Surg. 2006;244:400-9.

19. Seymour NE, Gallagher AG, Roman SA, O'Brien MK, Bansal VK, Andersen DK, et al. Virtual reality training improves operating room performance. Ann Surg. 2002;236:458-64. 